\title{
PERIODONTITIS AND OBESITY: A CROSS SECTIONAL SURVEY
}

\begin{tabular}{|l|l}
\hline Dental Science &
\end{tabular}

Dr. Neeta V. Head of the Department, Department of Periodontics, Govt. Dental College \& Hospital, Bhavsar

Ahmedabad, Gujarat-380016, India.

Dr. Shreeja Nair*

3rd year Post-graduate student, Department of Periodontics, Govt. Dental College \& Hospital, Ahmedabad, Gujarat-380016, India. ${ }^{*}$ Corresponding Author

Dr. Rahul Kasat

H 401, Arohi Elegance Near Aryan Gloria Gala Gymkhana Road South Bopal Ahmedabad 380058

Dr. Vasanthan. I

3rd year Post-graduate student, Department of Periodontics, Govt. Dental College \& Hospital, Ahmedabad, Gujarat-380016, India.

Dr. Swapna Patki

3rd Year Post-Graduate Student, Department of Periodontics, Govt. Dental College \& Hospital, Ahmedabad, Gujarat-380016

Dr. Rachana

Gaonkar

3rd Year Post-Graduate Student, Department of Periodontics, Govt. Dental College \& Hospital, Ahmedabad, Gujarat-380016

\section{ABSTRACT}

Background: The objective of this study is to determine whether there is an association between periodontitis and obesity among adults involved in this study.

Methods: In 2018, 200 subjects, > 19 years of age, who participated in this study were selected for analysis from the Department of Periodontology, Government Dental College and Hospital Ahmedabad. Participants underwent periodontal examination and anthropometric measurements and were asked to complete a socioeconomic status and overall health status questionnaire. Body mass index (BMI) and waist circumference (WC) have been used as overall body fat and upper body fat measurements. As established by the World Health Organization (WHO), standard BMI and WC cut off points were used. The Community Periodontal Index assessed the periodontal status and defined periodontitis as "code 3". Multivariate logistic regression analyses were performed, adjusting to the following variables: sex; age; household income; bedtime toothbrushing habits; use of dental floss; use of interproximal toothbrush; presence of active tooth decay; number of permanent teeth decayed, missing or filled; diabetes mellitus and smoking status.

Results: It was found that an association exit between periodontitis and high WC using the cut off points established by the WHO. Obese individuals with BMI average 25 had an adjusted odds ratio of 0.991 (0.806 to 1.220) for periodontitis. But it was found that a significant association between periodontitis and abdominal obesity. The adjusted odds ratio for periodontitis for obese subjects was 1.358 (confidence interval 1.003 to 1.839 ) after adjustment for all covariates.

Conclusions: A high WC denoting abdominal obesity was found to be associated to periodontitis, while BMI which often tends to misclassify as obese does not, appears to be associated with periodontitis. This finding shows a significant correlation between abdominal obesity and periodontitis.

\section{KEYWORDS}

Epidemiology; obesity; periodontitis, waist circumference, body mass index.

Obesity is increasing rapidly in both developed and developing countries. ${ }^{1,2}$ Obesity is linked to a number of life-threatening diseases, including hypertension, cardiovascular disease and type 2 diabetes mellitus (DM). ${ }^{3}$ These diseases are associated with adipokines secreted from adipose tissue, which plays a significant role in regulating metabolic and vascular biology. Some of these adipokines act locally, while others are released into the systemic circulation as signals to the liver, muscle and endothelium.

Adipokines play a variety of roles, including regulating blood pressure, promoting angiogenesis, contributing to type 2 DM development, and increasing systemic inflammation in general in the body. ${ }^{3,4}$ Periodontal disease is a general term used to describe diseases that affect the gingiva and cause damage to the supporting connective tissue and bone that anchor the teeth to the jaws. ${ }^{5}$ Periodontal disease is one of the world's most prevalent chronic diseases. ${ }^{6}$ There are several factors associated with an increased risk of periodontal disease including smoking, DM, osteoporosis, stress and age.

Many recent epidemiologic studies suggest an association between obesity and periodontal disease. ${ }^{8}$ In most studies an inverse relationship was found among adults between BMI and loss of clinical attachment and a positive correlation between bleeding on probing and BMI. Interestingly, studies based on regional and ethnic differences showed different results. Also, in some cases, only a limited section of the population may represent study groups, not the entire population. ${ }^{10}$

The purpose of this study is to investigate whether obesity is associated with periodontitis among a representative sample. Our hypothesis is that in obese people the prevalence of periodontitis is higher than in normal weight people.

\section{MATERIALS AND METHODS}

\section{Study Design and Subject Selection}

A total of 200 subjects aged $>19$ selected for the present study, from the Department of Periodontology, Government Dental College and Hospital Ahmedabad, providing data for one or more variables (periodontitis, BMI, WC, and confounders). All subjects were measured to evaluate periodontitis and BMI. The WC and periodontitis of 200 subjects were measured. All participants received written informed consent.

\section{Clinical Variables}

\section{Obesity variables.}

Obesity indicators used in this study were BMI and WC. BMI was calculated by dividing weight in kilograms by square height in meters. The World Health Organization (WHO) guideline for the classification of subjects based on BMI: 1) underweight $(<18.5 \mathrm{~kg} / \mathrm{m} 2)$; 2) normal weight (18.5 to $24.9 \mathrm{~kg} / \mathrm{m} 2)$; and 3 ) obese ( $225 \mathrm{~kg} / \mathrm{m} 2)$ were followed. ${ }^{11,12} \mathrm{WC}$ was measured at a midpoint between the lower border of the rib cage and the iliac crest by the WHO method. ${ }^{13}$ To categorize the subjects by WC, guidelines from the WHO were used. ${ }^{14}$ As recommended by the WHO guidelines WC cut off points (WC$\mathrm{WHO}$ ) were $>102 \mathrm{~cm}$ for males and $>88 \mathrm{~cm}$ for females.

\section{Periodontal disease.}

The WHO community periodontal index (CPI $)^{16}$ was used to assess 
periodontal conditions, and defined periodontal disease as a CPI score greater than or equal to "code 3 ." A CPI score of code 3 indicates that $>1$ site had a $>3.5-\mathrm{mm}$ pocket in the index teeth. Index teeth numbers taken were first and second molars in the all four quadrants and first incisors of first and third quadrant. A specially designed, thin handled and lightweight (5 gm) CPI probe with a ball tip of $0.5 \mathrm{~mm}$ and a black band between $3.5 \mathrm{~mm}$ and $5.5 \mathrm{~mm}$ as well as black rings at $8.5 \mathrm{~mm}$ and $11.5 \mathrm{~mm}$ which met the guidelines of the WHO was used. ${ }^{17}$ The mouth was split into sextants and the index tooth was measured. If in a sextant qualifying for examination, no index teeth were present, all remaining teeth were examined and the highest score was recorded as the score for that sextant. A sampling force of $20 \mathrm{~g}$ was used. The tip of the probe was gently inserted into the gingival sulcus or pocket and the sulcus or pocket total extent was explored. ${ }^{18}$

\section{Covariates.}

Covariates which were selected for this study were sociodemographic variables and risk factors associated with periodontal disease. The covariates were classified into three groups. The first group consisted of variables of sociodemographic variates: sex, age, and income from households. Age groups in 10-year units were categorized. Household income was an adjustment of family income to the number of family members. Household income was divided into four categories. The second group included variables associated with oral health behaviours, such as brushing twice daily, dental floss use, and interproximal toothbrush use. The third group consisted of variables related to oral and general health status, such as DM and smoking status correlated with periodontitis. ${ }^{19} \mathrm{DM}$ and smoking status information was obtained from self - reported questionnaires. The subjects were divided into three groups according to smoking status: 1) non - smokers: those who had never smoked or smoked $<100$ cigarettes in their lives; 2) current smokers: those who currently smoked and smoked < 100 cigarettes; and 3) past smokers: those who smoked in the past but stopped smoking. It was adjusted sequentially for the three covariate groups, model 1 to model 3, when analysing data using the multivariate logistic regression model.

\section{Statistical analyses.}

Differences among the groups were analysed using the $\mathrm{X}^{2}$ test. Multivariate logistic regression analyses were applied to examine the cross-sectional relationships between BMI or WC, and CPI, adjusting for the effects of the previously mentioned covariables.

\section{RESULTS}

Characteristics of the study subjects categorized by obesity status such as BMI and WC (WC cut-off point followed by the WHO) are shown in Tables 1 and 2. The relationship between CPI and covariates were confirmed by $t$ test. Most of the covariates except interproximal toothbrushing ( $\mathrm{P}=0.19$ ) were significantly correlated with CPI ( $\mathrm{P}$ $<0.01)$.

Distribution of Sociodemographic Variables, Oral Health Behaviour, and General and Oral Health Status by BMI

\begin{tabular}{|c|c|c|c|c|c|}
\hline \multirow{2}{*}{ Variables } & & \multicolumn{3}{|c|}{ BMI } & \multirow{2}{*}{ P value } \\
\hline & & $<18.5$ & \begin{tabular}{|l|}
$18.5-24.9$ \\
\end{tabular} & $>25$ & \\
\hline \multirow[t]{5}{*}{ Age } & $19-29$ & 1 & 3 & 14 & \multirow[t]{5}{*}{0.038} \\
\hline & $30-39$ & 2 & 12 & 65 & \\
\hline & $40-49$ & 2 & 15 & 49 & \\
\hline & $50-59$ & 1 & 4 & 21 & \\
\hline & $60-69$ & 0 & 3 & 8 & \\
\hline \multirow[t]{2}{*}{ Gender } & Male & 4 & 23 & 72 & \multirow[t]{2}{*}{0.014} \\
\hline & Female & 2 & 14 & 85 & \\
\hline \multirow[t]{4}{*}{ Income } & $<25$ & 4 & 12 & 27 & \multirow[t]{4}{*}{0.02} \\
\hline & $25-49$ & 1 & 13 & 56 & \\
\hline & $50-75$ & 1 & 7 & 59 & \\
\hline & $>75$ & 0 & 5 & 15 & \\
\hline \multirow[t]{2}{*}{ Brushing } & Once & 4 & 29 & 121 & \multirow[t]{2}{*}{0.021} \\
\hline & Twice & 2 & 8 & 36 & \\
\hline \multirow[t]{2}{*}{ Inter dental aids } & Yes & 2 & 5 & 43 & \multirow[t]{2}{*}{0.19} \\
\hline & No & 4 & 32 & 114 & \\
\hline \multirow[t]{2}{*}{ Periodontitis } & No & 0 & 13 & 59 & \multirow[t]{2}{*}{0.00024} \\
\hline & Yes & 6 & 24 & 98 & \\
\hline \multirow[t]{2}{*}{$D M$} & No & 4 & 19 & 81 & \multirow[t]{2}{*}{0.00046} \\
\hline & Yes & 2 & 18 & 76 & \\
\hline \multirow[t]{3}{*}{ Smoking } & Non smoker & 3 & 15 & 45 & \multirow[t]{3}{*}{0.042} \\
\hline & Current smoker & 2 & 14 & 59 & \\
\hline & Past Smoker & 1 & 8 & 53 & \\
\hline
\end{tabular}

Table 1 shows the study population characteristics related to sociodemographic, oral health behaviour, and general and oral health status by BMI. There were more obese males than females $(\mathrm{P}=0.014)$. Both household income $(\mathrm{P}=0.02)$ and oral health behaviour was significantly different among the three groups. The prevalence of periodontitis was significantly different among three BMI groups ( $\mathrm{P}$ $<0.001)$. DM was more prevalent in the obese people $(\mathrm{P}<0.001)$.

Distribution of Sociodemographic Variables, Oral Health Behaviour, and General and Oral Health Status by WC

\begin{tabular}{|c|c|c|c|c|}
\hline \multirow[t]{2}{*}{ Variables } & & \multicolumn{2}{|c|}{ WC } & \multirow[t]{2}{*}{ P value } \\
\hline & & $>102 \mathrm{~cm} / 88 \mathrm{~cm}$ & $<101 \mathrm{~cm} / 87 \mathrm{~cm}$ & \\
\hline \multirow[t]{5}{*}{ Age } & $19-29$ & 16 & 2 & \multirow[t]{5}{*}{0.00025} \\
\hline & $30-39$ & 62 & 17 & \\
\hline & $40-49$ & 52 & 14 & \\
\hline & $50-59$ & 16 & 10 & \\
\hline & $60-69$ & 9 & 2 & \\
\hline \multirow[t]{2}{*}{ Gender } & Male & 80 & 19 & \multirow[t]{2}{*}{0.00026} \\
\hline & Female & 75 & 26 & \\
\hline \multirow[t]{4}{*}{ Income } & $<25$ & 27 & 16 & \multirow[t]{4}{*}{0.00045} \\
\hline & $25-49$ & 55 & 15 & \\
\hline & $50-75$ & 57 & 10 & \\
\hline & $>75$ & 16 & 4 & \\
\hline \multirow[t]{2}{*}{ Brushing } & Once & 123 & 31 & \multirow[t]{2}{*}{0.014} \\
\hline & Twice & 32 & 14 & \\
\hline \multirow{2}{*}{$\begin{array}{l}\text { Inter dental } \\
\text { aids }\end{array}$} & Yes & 41 & 9 & \multirow[t]{2}{*}{0.037} \\
\hline & No & 114 & 36 & \\
\hline \multirow{2}{*}{$\begin{array}{l}\text { Periodontiti } \\
s\end{array}$} & No & 53 & 19 & \multirow[t]{2}{*}{0.00032} \\
\hline & Yes & 102 & 26 & \\
\hline \multirow[t]{2}{*}{$D M$} & No & 82 & 22 & \multirow[t]{2}{*}{0.00043} \\
\hline & Yes & 73 & 23 & \\
\hline \multirow[t]{3}{*}{ Smoking } & Non smoker & 50 & 13 & \multirow[t]{3}{*}{0.00032} \\
\hline & $\begin{array}{l}\text { Current } \\
\text { smoker }\end{array}$ & 61 & 14 & \\
\hline & Past Smo & 44 & 18 & \\
\hline
\end{tabular}

Table 2 shows the study population characteristics related to sociodemographic, oral health behaviour, and general and oral health status categorized by WC following the WHO guidelines. Here, it was observed that more significant differences in the prevalence of obesity between the male and female subjects than in Table $2(\mathrm{P}<0.001)$. An association was found between age group and periodontitis $(\mathrm{P}<0.001)$. In addition, the rate of obesity decreased with increase in household income $(\mathrm{P}<0.001)$. An association was also found between use of inter-proximal toothbrushing and obesity $(\mathrm{P}=0.037)$. People with high WC had periodontitis more frequently than those with normal WC (P $<0.001)$. The prevalence of DM was higher in obese people than in normal people. The smoking status was significantly different, unlike other tables $(\mathrm{P}<0.001)$

\section{DISCUSSION}

In the present study, after adjustment for sociodemographic variables, oral health behaviour, and general and oral health status, a significant association was found between obesity and the prevalence of periodontitis, particularly using the WHO criteria for WC. Obese individuals had higher periodontitis rates than those with normal WC. There was no significant association between periodontitis and obesity with BMI. This finding shows that high WC is correlated with periodontitis.

Several recent studies have also shown a positive correlation between obesity and periodontitis, but this correlation has not been found by some others. A systematic review found that obesity with high WC or high BMI was associated with periodontitis in young adults. ${ }^{20}$ This association was found only for those in the young adult group. The researchers reasoned that the oral health of young adults is less affected by aging and that tooth decay is more dependent on diet, compared to middle-aged and older adults.

In a study by Khader et al. ${ }^{21}$ showed that BMI and WC were highly correlated with periodontitis, but the waist-to-hip ratio (WHR) was not correlated. A positive correlation between obesity and periodontitis was found in several studies..$^{22,23,24}$ However, Linden et al. ${ }^{16}$ reported that there was no significant relation between BMI and severe periodontitis among 60-to 70-year-old Western European men. In a study by 
Ylostalo et al. ${ }^{25}$ did not find any positive correlation between body weight and periodontal infection in 2,841 non-diabetic people aged 30 to 49 years. Interestingly, in a study by Kongstad ${ }^{26}$ found BMI to be inversely related to clinical attachment loss among 1,504 subjects. Results from the United States, Brazil, Japan, and the Middle East showed a positive association, although results from Western and Northern Europe were not significant in general. ${ }^{10}$ It seems that the distribution of association between obesity and periodontitis differs by region and race.

As a measure of obesity, BMI and WC was used. Height and weight are the simplest and commonly used measures, and a number of indices have been developed, including the widely used BMI, which is defined as weight in kilograms divided by the square of height in meters. BMI generally co-relates highly with adiposity, although it can some-times misclassify total body fat content. For example, sportspersons who are muscular have a high BMI, because muscles weigh more than fat, and have BMIs in the overweight range, even though they are not obese. ${ }^{27}$ The shortest and tallest subjects also tend to be misclassified as obese. This study showed a similar result. The degree of coincidence between $\mathrm{BMI}$ and WC for obesity was also analysed.

Although in some Asian populations the prevalence of obesity is lower than in Europe, the health risks associated with obesity occur at lower body mass in Asian people. As such, the current WHO criteria used to define overweight and obesity using BMI may not be appropriate for some populations. It is not just the amount of body fat but also its distribution that determines risk associated with obesity. Abdominal or visceral fat is associated with the cardiovascular risk factors of metabolic syndrome. Waist- Hip- Ratio (WHR) is also used as a measure of abdominal obesity. Although WHRs are identified with abdominal fat accumulation, WC is the preferred measure of abdominal obesity. ${ }^{27}$ Large studies have indicated that measurement of WC or WHR may be a better disease risk predictor than BMI, and a research to determine whether BMI, WC, or both should be used to assess disease risk is also available.

In the present study, WC cut-off point as given by the World Health Organization was used. It was found that WC was positively correlated with periodontitis, whereas BMI was not similarly co-related. This means that abdominal or visceral fat accumulation is a better indicator of periodontal status than total body fat. When the WC cut-off points established by the WHO were used, the correlation was even stronger. This indicates that morbid abdominal obesity is more strongly associated with periodontitis than moderate abdominal obesity.

To determine the cross-sectional relationship between obesity and periodontitis, multivariate logistic regression models were designed for this study. The correlation between obesity (based on WC) and periodontitis remained significant when adjustment were made for sociodemographic variables, oral health behaviour, and general and oral health status, although smoking status and DM are widely recognized as risk factors for periodontitis

Few studies exist on the possible mechanisms linking obesity to periodontal disease. However, a recent review postulates that adipose tissue secretes a bioactive substance known as "adiopocytokine, "which may directly injure periodontal tissue.$^{28}$ Plasminogen activator inhibitor-1 expressed in visceral fat inducing the agglutination of visceral blood and raising the risk of ischemic vascular disease may also decrease blood flow in the periodontium of obese subjects, thus promoting the development of periodontal disease. ${ }^{28}$ Another mechanism was related to oral bacteria. Goodson et al. proposed that obese people may have different kinds of oral bacteria from normalweight people, which might lead to periodontal disease. ${ }^{29}$

As one of the limitations in this study, periodontal status was assessed by CPI. Although CPI is an easier way to evaluate periodontal treatment need in community settings, it could overestimate the prevalence of periodontitis because it includes pseudo pockets. Also, the use of representative teeth may underestimate the prevalence. Another limitation is that because this study adopted a cross-sectional design, it was not able to find the cause-effect relationship between obesity and periodontitis.

Nevertheless, it was found that a significant association was present between abdominal obesity and periodontitis with adjusting for many variables, especially for present smoking status and DM. It would be meaningful to have studies on obesity and periodontitis. Prospective cohort studies may be helpful to find out the cause- effect relationship between periodontitis and obesity.

\section{CONCLUSIONS}

Obesity as defined using WC seems to be associated with periodontitis, whereas obesity as defined by BMI does not seem to be correlated to periodontal disease. Also, abdominal obesity is a suitable measurement in examining the relationship between periodontitis and obesity.

\section{REFERENCES}

Prentice AM. The emerging epidemic of obesity in developing countries. Internationa journal of epidemiology. 2006 Feb 1;35(1):93-9.

Kopelman PG. Obesity as a medical problem. Nature 2002; 404:634-643

3. Stringer DM, Sellers EA, Burr LL, Taylor CG. Altered plasma adipokines and marker of oxidative stress suggest increased risk of cardiovascular disease in First Nation youth with obesity or type 2 diabetes mellitus. Pediatric diabetes. 2009 Jun;10(4):269-77.

Ouchi N, Parker JL, Lugus JJ, Walsh K. Adipokines in inflammation and metabolic disease. Nature reviews immunology. 2011 Feb;11(2):85-97.

5. Listgarten MA. Pathogenesis of periodontitis. Journal of clinical periodontology. 1986 May;13(5):418-25.

6. Petersen PE, Ogawa $\mathrm{H}$. The global burden of periodontal disease: towards integration with chronic disease prevention and control. Periodontology 2000 2012 Oct;60(1):15-39. Genco RJ, Borgnakke WS. Risk factors for periodontal disease. Periodontology 2000 2013 Jun;62(1):59-94.

8. Martinez-Herrera M, Silvestre-Rangil J, Silvestre FJ. Association between obesity and periodontal disease. A systematic review of epidemiological studies and controlled clinical trials. Medicina oral, patologia oral y cirugia bucal. 2017 Nov;22(6): e708

9. Kongstad J, Hvidtfeldt UA, Grønbæk M, Stoltze K, Holmstrup P. The relationship between body mass index and periodontitis in the Copenhagen City Heart Study. Journal of periodontology. 2009 Aug;80(8):1246-53

10. Kim EJ, Jin BH, Bae KH. Periodontitis and obesity: A study of the fourth Korea national health and nutrition examination survey. Journal of periodontology. 2011 Apr;82(4):533-42.

11. De Onis M, Habicht JP. Anthropometric reference data for international use: recommendations from a World Health Organization Expert Committee. The American journal of clinical nutrition. 1996 Oct 1;64(4):650-8.

12. Prentice AM, Jebb SA. Beyond body mass index. Obesity reviews. 2001 Aug;2(3):141-7.

13. Ross R, Berentzen T, Bradshaw AJ, Janssen I, Kahn HS, Katzmarzyk PT, Kuk JL, Seidell JC, Snijder MB, Sørensen TI, Després JP. Does the relationship between wais circumference, morbidity and mortality depend on measurement protocol for wais circumference, morbidity and mortality depend on
circumference? Obesity reviews. 2008 Jul; $9(4): 312-25$

14. Nishida C, Ko GT, Kumanyika S. Body fat distribution and noncommunicable disease in populations: overview of the 2008 WHO Expert Consultation on Wais Circumference and Waist-Hip Ratio. European journal of clinical nutrition. 2010 Jan;64(1):2-5

15. El Sayed Amin H. Relationship between overall and abdominal obesity and periodontal disease among young adults. EMHJ-Eastern Mediterranean Health Journal, 16 (4), 429$433,2010.2010$

16. Linden G, Patterson C, Evans A, Kee F. Obesity and periodontitis in 60-70-year-old men. J Clin Periodontol 2007; 34:461-466.

17. Ramachandra SS, Mehta DS, Nagarajappa Sandesh M, Vidya Baliga M, Janardhan Amarnath M. Periodontal probing systems: a review of available equipment Periodontics. 2009 May;3(3)

18. World Health Organization. Epidemiology, Etiology and Prevention of Periodontal Diseases. Report of a WHO Scientific Group. Geneva, Switzerland: World Health Organization; 1978. Technical Report Series No. 621 .

19. Bridges RB, Anderson JW, Saxe SR, Gregory K, Bridges SR. Periodontal status of diabetic and non-diabetic men: Effects of smoking, glycemic control, and socioeconomic factors. Journal of periodontology. 1996 Nov;67(11):1185-92.

20. Khan S, Barrington G, Bettiol S, Barnett T, Crocombe L. Is overweight/obesity a risk factor for periodontitis in young adults and adolescents? a systematic review. Obesity reviews. 2018 Jun;19(6):852-83.

21. Khader YS, Bawadi HA, Haroun TF, Alomari M, Tayyem RF. The association between periodontal disease and obesity among adults in Jordan. J Clin Periodontol 2009; 36:18-24

22. Dalla Vecchia CF, Susin C, Ro"sing CK, Oppermann RV, Albandar JM. Overweight an obesity as risk indicators for periodontitis in adults. J Periodontol 2005; 76:1721-1728.

3. Linden G, Patterson C, Evans A, Kee F. Obesity and periodontitis in 60-70-year-old men. J Clin Periodontol 2007; 34:461-466.

24. Sarlati F, Akhondi N, Ettehad T, Neyestani T, Kamali Z. Relationship between obesity and periodontal status in a sample of young Iranian adults. Int Dent J 2008; 58:36-40.

25. Ylo"stalo P, Suominen-Taipale L, Reunanen A, Knuuttila M. Association between body weight and periodontal infection. J Clin Periodontol 2008; 35:297-304.

26. Kongstad J, Hvidtfeldt UA, Grønbaek M, Stoltze K, Holmstrup P. The relationship between body mass index and periodontitis in the Copenhagen City Heart Study. J Periodontol 2009; 80:1246-1253.

27. World Health Organization Regional Office for the Western Pacific (WPRO), the International Association for the Study of Obesity (IASO) and the International Obesity Task Force (IOTF). The Asia-Pacific perspec-tive: Redefining obesity and its treatment. New South Wales: Health Communications Australia Pty Ltd;2000:17-19.

28. Saito T, Shimazaki Y. Metabolic disorders related to obesity and periodontal disease. Periodontol 2000 2007; 43:254-266.

29. Goodson JM, Groppo D, Halem S, Carpino E. Is obesity an oral bacterial disease? J Den Res 2009; 88:519-523. 